DOI: 10.5604/01.3001.0013.2539

\title{
TOWARDS A DIFFERENT WORLD - ON THE POTENTIAL OF THE INTERNET OF EVERYTHING
}

\author{
Mirosław Płaza, Radosław Belka, Zbigniew Szcześniak \\ Kielce University of Technology, Faculty of Electrical Engineering, Automatic Control and Computer Science
}

Abstract. Internet-based technologies are moving faster and faster into many spheres of our lives and at the same time are a key component of the ongoing technological revolution, which is why there are many ongoing scientific projects aimed at their development. The article presents a discussion on the development of Internet-based technologies known as the Internet of Everything (IoE). The paper presents the areas in which these technologies are most often used. A multi-layered reference model and a procedure for subsequent actions in designing innovative solutions in this area are presented.

Keywords: Internet of Everything, Network, Telecommunication network, Cyberspace, Big Data analytics

\section{W STRONE INNEGO ŚWIATA - CZYLI O POTENCJALE INTERENTU WSZECHRZECZY}

Streszczenie. Technologie internetowe wkraczają coraz szybciej w liczne sfery naszego życia i jednocześnie stanowia kluczowy komponent trwającej dziś rewolucji technologicznej, dlatego też prowadzonych jest obecnie wiele projektów naukowych ukierunkowanych na ich rozwój. Artykut przedstawia dyskusje dotyczaca rozwoju technologii internetowych znanych pod nazwa Internetu wszechrzeczy (IoE). W pracy pokazano obszary, w których technologie te znajduja najczęściej zastosowania. Przytoczono wielowarstwowy model referencyjny oraz procedurę kolejnych działań przy projektowaniu nowatorskich rozwiazań w tym zakresie.

Słowa kluczowe: Internet wszechrzeczy, sieć teleinformatyczna, cyberprzestrzeń, analityka Big Data

\section{Introduction}

The history of humanity has been repeatedly shaped by the achievements of science and progress in the development of new technologies. Civilisation would not be at its current level of advancement if it were not for a series of innovative solutions from different areas of science gradually adopted over subsequent centuries. The invention in the past of things we consider basic today, such as the wheel, writing, paper or print, was undoubtedly an important point in our history. The discovery of paper and printing has led to real revolutions in the area of communication and transfer of information between people. The discoveries of the 19th and 20th centuries were of great importance in the field of human communication. The invention of the telephone, car, radio or television revolutionised people's lives and, above all, made them easier. Today, these technologies are constantly evolving, introducing new solutions and services, which would not be possible without further inventions, such as computers and Internet technologies. The first computer in history is considered to be the ENIAC. As a curiosity it is worth mentioning that it occupied $167 \mathrm{~m}^{2}$ of area, consisted of 42 cabinets, reached over 2.6 meters in height and measured 24 meters in length. In turn, its total weight exceeded 27 tonnes [7, 8]. By comparison, the smallest computer today, developed by Michigan scientists, is only 0.3 millimetres long [24]. This example shows how fast and effective can the development of teleinformatic technologies be in present times. Nowadays, the complexity of the infrastructure and requirements for the specialised systems, force their designers to introduce interdisciplinary solutions from various fields of science combining issues from within computer science, telecommunication, electronics, electrical engineering or others areas $[14,15,16]$.

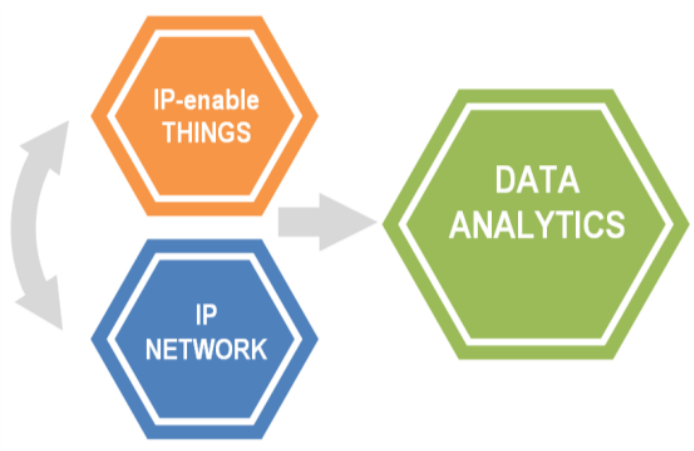

Fig. 1. A diagram presenting the idea of the IoT technology
The Internet of Things (IoT) concepts are currently one of the fastest growing ICT technologies, which have a significant impact on and benefit science and the economy. These solutions are based on the idea of linking everyday objects into a computer network, mainly for the exchange, processing and analysis of data. A simple diagram on figure 1 visualizing the idea of IoT technology.

The Internet of Things has been functioning in global solutions for many years, although not directly under the current name. So far, it has included the notions of telemetry, intelligent cities and buildings, sensory networks or other solutions based on technological applications of computer networks. The lack of detailed legal regulations and target standardisation in this area translates into the emergence of many separate terms for this concept used by scientific institutions, manufacturers of hardware or software. This means that due to its scale, innovation and constant dynamic development, a clear definition of the IoT issue is not a simple task. From the literature of the world we learn that the IEEE describes the concepts of IoT as: "A network of items each embedded with sensors - which are connected to the Internet" [10]. In the ITU recommendation [18] the Internet of Things is defined as: "A global infrastructure for the information society, enabling advanced services by interconnecting (physical and virtual) things based on existing and evolving interoperable information and communication technologies". Another noteworthy definition of the IoT technology was proposed by the OASIS association: "System where the Internet is connected to the physical world via ubiquitous sensors" [4]. One step further in defining IoT was taken by the world leader in ICT - Cisco, dubbing the discussed solutions the Internet of Everything (IoE). According to [3], the Internet of Everything is "bringing together people, process, data and things to make networked connections more relevant and valuable than ever before, turning information into actions that create new capabilities, richer experiences and unprecedented economic opportunity for businesses, individuals and countries". The Internet of Everything is a natural successor to the concept of the Internet of Things, successfully entering today into many spheres of our lives, and at the same time being a key component of the technological revolution known as Industry 4.0 [23], incorporating into the web everything that has not yet been connected.

\section{Connecting unconnected}

The Internet of Everything is a network which is created with the use and adoption of existing solutions, among others, in the field of computer science, ICT, sensorics, automation, electronics or data analytics. Everything that has not yet been incorporated 
into the global network infrastructure may soon become a part of it. This is largely due to the constant development of Internet protocols, which provide broad perspectives for the use of modules compatible with Ethernet, TCP/IP, Wi-Fi or LoRaWAN standards. The application potential of IoT/IoE solutions is practically unlimited. It includes for example: smart homes / buildings / cities, smart health solutions, smart businesses and industry, smart energy systems and grids, distributed metering systems or threat monitoring systems. A very important and at the same time popular issue is the application of the discussed technologies in environmental protection measures [17], which are related to e.g. monitoring of air, soil or water pollution. The positive impact on the environment is also reflected in the low energy consumption of equipment implemented in the IoT/IoE technologies, thus making the discussed solutions extremely important from the point of view of global problems. Other popular trends in the development of the described solutions are real-time object localization systems implemented in many branches of industry and business $[1,11,12,13]$. Table 1 shows the areas where IoT/IoE projects have the widest applications [20]. The presented data show that the trend associated with the concepts of Smart City and Connected Industry is decidedly dominant. The use of these technologies in Connected Building, Connected Car and Smart Energy is at a slightly lower level. Other industries use modern Internet-based technologies to a lesser extent.

Table 1. Areas of application of IoT technologies [13]

\begin{tabular}{|l|c|}
\hline \multicolumn{1}{|c|}{ IoT/IoE Segment } & Number of IoT projects \\
\hline Smart City & $23 \%$ \\
\hline Connected Industry & $17 \%$ \\
\hline Connected Building & $12 \%$ \\
\hline Connected Car & $11 \%$ \\
\hline Smart Energy & $10 \%$ \\
\hline Other & $8 \%$ \\
\hline Connected Health & $6 \%$ \\
\hline Smart Supply Chain & $5 \%$ \\
\hline Smart Agriculture & $4 \%$ \\
\hline Smart Retail & $4 \%$ \\
\hline
\end{tabular}

A large set of Internet of Everything devices, which are combined in a single global network infrastructure, creates a powerful tool that can be adapted to different needs. However, this requires the integration of interdisciplinary solutions from the field of, among others, sensors, electronics, wireless communication, automation, information distribution networks, or data analytics or machine learning. The combination of all or some of these elements will ensure the learning of new, undiscovered knowledge.

\section{Gathering the knowledge}

One of the intentions of the implemented IoE solutions is to acquire large amounts of data, which after the initial acquisition and initial processing are sent through the web to the data centres for further processing and practical use. In the era of today's technological solutions, especially omnipresent video monitoring [9], these are usually very large data sets, in the analysis of which conventional statistical methods are not applicable. In addition, the literature indicates that the amount of data sent over the web will increase significantly in the coming years. According to the report Cisco Global Cloud Index: Forecast and Methodology [5], global Data Centers in 2021 will process 20 trillion of bytes of data per year, and this number will increase annually by an average of 20 $25 \%$. These data may come in unexpectedly and in various forms - they may be e.g. unstructured and/or non-relational, and additionally they do not always have to be reliable. Therefore, an important challenge for data analytics is to extract useful knowledge from the generated stream of diversified and difficult to interpret information sets. For this reason, the concepts of the Internet of Everything are usually based on innovative issues related to Big Data analytics. Big Data includes working with data that is compatible with the $4 \mathrm{~V}$ model (Volume, Velocity, Veracity,
Value) [19]. In the context of Big Data analytics methods, cloud computing (SaaS, PaaS), distributed file systems (Hadoop), parallel processing platforms (MapReduce), non-relational databases (noSQL), machine learning and artificial intelligence are also important. The way in which we obtain, send, store, secure and interpret information is the primary task of Big Data. In addition, Big Data methods have changed the approach to Analytic Lifecycle issues, which is presented on figure 2.

\section{CLASSIC SCHEME}

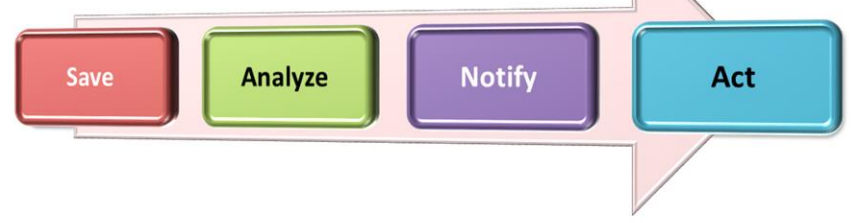

\section{BIG DATA SCHEME}

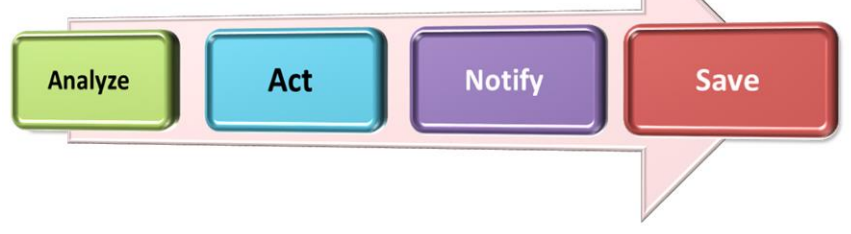

Fig. 2. Classic and Big Data schemes for Analytics Lifecycle

From the traditional Save - Analyse - Notify - Act scheme we move to the much more challenging scheme: Analyse - Act Notify - Save [2]. The difference in the approach to Big Data issues in relation to conventional methods is apparent, among others, through the preliminary analysis of data already performed at the stage of their acquisition. Only data relevant to the examined problem are saved. All other data can be filtered out using network edge elements, e.g. single-board computers (SBC) as Raspberry Pi. It is the responsibility of the Edge Computing layer integrated into the multilayer reference model developed for Internet of Everything technologies, shown in figure 3.

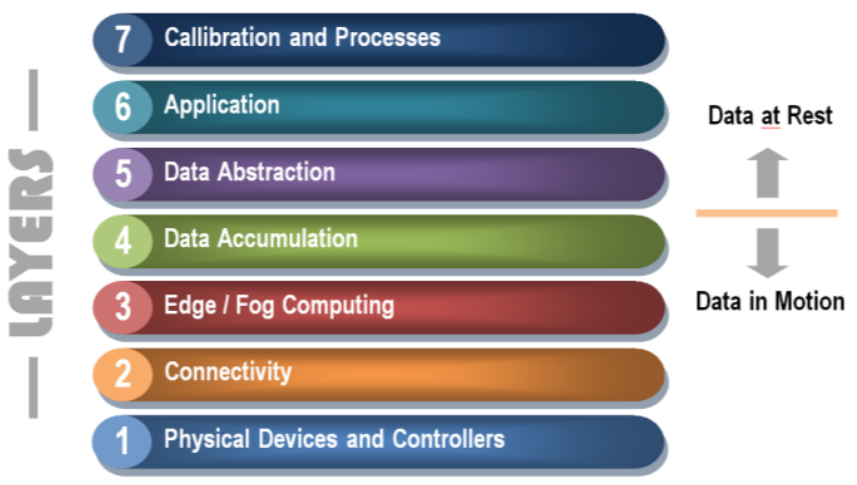

Fig. 3. A multi-layer reference model for the IoE technology [21]

Physical Devices and Controllers layer is a collection of all "things" connected to the IoE infrastructure. These include, for example: precise real-time object location systems, video systems and various sensor networks. Thanks to the functionality of the second layer, these elements can communicate with each other, using dedicated network solutions, cooperating and generating large amounts of data pre-filtered at the level of the third layer. The filtered data are stored in the Data Accumulation layer and prepared for further applications and analysis in the Data Abstraction layer. Next, they are passed in a structured format to the Application layer, where they should be properly interpreted according to their specific applications. The top layer includes different areas of application of the received data in the implemented solutions [21]. 


\section{Towards the another (better?) World}

A Sustainability Summit was held in September 2015 in New York City, where the international community adopted a new world development plan until 2030 in the form of a Sustainable Development Agenda (Agenda 2030) [22]. The new Agenda contains 17 sustainable development objectives and 169 tasks to be achieved. Many of the agenda's guidelines pose new challenges to the Internet of Everything technology. Figure 4 presents a workflow showing subsequent sequences of activities aimed at using modern technologies from the IoE area in designing solutions for the needs of today's civilization.

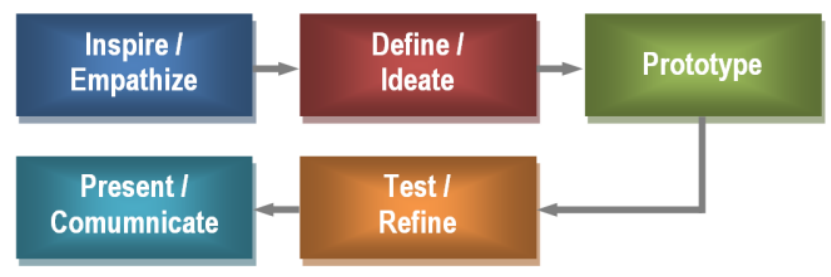

Fig. 4. IoE systems designing process [6]

Analysing Figure 4, we can notice that the whole process of action in designing innovative solutions begins with inspiration against the needs and stirring the empathy of the audience. This means that one of the most important elements is a suitably attractive, needs-oriented idea. Then, using the latest achievements in the field of modelling, prototyping, implementation and testing of ICT systems and Internet of Things technologies, we should strive to achieve the intended objectives. It is important to note that current technical solutions in the field of sensor electronics (nanoelectronics), localization and communication technologies (e.g.: RFID-2gen, IBeacon, Cisco Hyperlocation, UWB, NB-IoT, LoRaWAN), microcontrollers and single-board computers (e.g.: Arduino, SBC Raspberry Pi, ESP32, Rock Pi, Banana Pi and other), secure IPv6 network technologies (VPN, ASA, Cisco ISR, Meraki AP), as well as the availability of platforms and programming libraries used in the implementation of machine learning algorithms (e.g.: TensorFlow, PyTorch, Keras, scikitlearn-on Github-type public platforms) provide the possibility to create useful, competitive, flexible, scalable, secure and transparent IoE networks.

In reference to the concepts presented above and in order to meet human needs, visions of strictly pro-social projects are already proposed. One example is the PRO-HOMINIS System (PROgressive Health-Oriented Motivation System), proposed by us, based on the IoE Novel-Innovative Solution. This system is a concept of an intelligent tool activating its users to greater physical activity, which is also to contribute to the prevention of civilisation diseases of our times. As the proposed PROHOMINIS name suggests, the system would motivate people to be more active by monitoring their behaviour, in a way forcing them to visit specific places on a digital map of the area.

Another concept is the TARGET - "Tracking Adopted, Routing Guide application for Effective Transport" The task of the system would be to adapt the route strategy based on the technology of distributed sensory networks. This system would represent a product innovation for existing GPS-based transport monitoring systems. Thanks to IoE solutions and metaheuristic optimization algorithms, including the latest developments in Swarm Intelligence, it would be possible to create a product enabling reduction of direct and indirect costs of passenger and freight transport, as well as to reduce the energy consumption of the currently operating transport fleets.

The above-mentioned examples of projects utilising the Internet of Everything are clearly in line with the sustainable development objectives set out in the above-mentioned agenda [22]. The current literature also describes many other interesting examples which can be successfully implemented in the near future and which will be targeted at certain groups or even entire societies. It should be remembered that the broadly understood science and technology should serve primarily the common good, contribute to solving various social problems and achieve the intended objectives of specific social groups and individuals. At the same time, they should provide a wide range of ideas, concepts, solutions and innovations. Analysing the fate of humanity, one can easily point to many examples where science and technology were used in a way that threatened man. However, it is worth trusting that the Internet of Everything will bring spectacular benefits in solving both local and global socioeconomic problems.

\section{Conclusion}

Generally speaking, the idea of implementing IoE systems involves the acquisition of sensory information (data) by means of distributed networks, which, transformed by successive layers of the reference model, constitute knowledge that brings significant benefits to the beneficiaries of these systems. It should also be noted that the Internet of Everything is first and foremost about the "Internet of Ideas", because the measure of these benefits depends on properly set goals and proper implementation of the IoE architecture. A great advantage of the devices used in the IoE is their low energy consumption, which in itself is a measurable benefit for both the beneficiary and our environment.

Currently in Poland the market of services related to IoT/IoE is developing very dynamically, annually increasing the number of its customers. This changes the quality of life in the society, but at the same time introduces new threats. In many cases there are problems with protecting the processed data. Therefore, in parallel with the development of IoT/IoE, a lot of cybersecurity research is being carried out.

Today, there are no ideal solutions that could fully exploit the potential of the Internet of Everything technologies yet. It is possible that such solutions will appear with the arrival of the $5 \mathrm{G}$ network, because the potential for IoE applications is immense. In December 1959, the renowned physicist Richard Feynmann said the famous words "There is plenty of room at the bottom", outlining the application potential of nanotechnology. Similarly, one could say "There is plenty of room on the Internet of Everything".

\section{Acknowledgment}

This paper was supported by the European Union's Smart Growth Operational Programme 2014-2020, under grant agreement no POIR.04.01.02-00-0041/17-00, „CyberMatryca Integrated Visitors' Support Systems“"

\section{References}

[1] Belka R., Deniziak S., Płaza M., Hejduk M., Pięta P., Płaza M., Czekaj P., Wołowiec P., Ludwinek K.: Integrated Visitor Support System for Ttourism Industry Based on IoT Technologies. Proceedings of SPIE, Photonics Applications in Astronomy, Communications, Industry, and High-Energy Physics Experiments, Wilga 2018, 108081J [DOI: 10.1117/12.2326403].

[2] Belka, R.: An Indoor Tracking Systems and Pattern Recognition Algorithms as Key Components of IoT-based Entertainment Industry. Proceedings of SPIE, Photonics Applications in Astronomy, Communications, Industry, and HighEnergy Physics Experiments, Wilga 2019, 11176.

[3] Bradley J., Barbier J., Handler D.: Embracing the Internet of Everything to Capture Your Share of \$14.4 Trillion. Cisco, 2013.

[4] Camarinha-Matos L. M., Tomic S., Graca P.: Technological Innovation for the Internet of Things. 4th IFIP WG 5.5/SOCOLNET Doctoral Conference on Computing, Electrical and Industrial Systems - DoCEIS, Costa de Caparica 2013, 3-12.

[5] Cisco Company.: Cisco Global Cloud Index: Forecast and Methodology 20162021. Cisco, November 19, 2018, 1-46.

[6] Cisco Company.: IoT - Connecting Things. Course Materials. Cisco Networking Academy, 2019.

[7] Cleveland D.: Seven Wonders of Communication. Twenty-First Century Books, Minneapolis 2010

[8] Goldstine H. H., Goldstine A.: The Electronic Numerical Integrator and Computer (ENIAC). IEEE Annals of the History of Computing 18/1996, 10-16 [DOI: $10.1109 / 85.476557]$

[9] Królikowski M., Płaza M., Szcześniak, Z.: Chosen Sources of Signal Interference in HD-TVI Technology. Proceedings of SPIE, Photonics Applications in Astronomy, Communications, Industry, and High-Energy Physics Experiments, Wilga 2017, 104455M [DOI: 10.1117/12.2280534]. 
[10] Minerva R., Biru A., Rotondi D.: Towards a Definition of the Internet of Things IEEE Internet Initiative. Telecom Italia, Torino 2015.

[11] Pięta P., Deniziak S., Belka R., Płaza M., Płaza M.: Multi-domain Model for Simulating Smart IoT-based Theme Parks. Proceedings of SPIE, Photonics Applications in Astronomy, Communications, Industry, and High-Energy Physics Experiments, Wilga 2018, 108082T [DOI: 10.1117/12.2501659A].

[12] Płaza M., Belka R., Płaza M., Deniziak S., Pięta P., Doszczeczko S. Analysis of Feasibility and Capabilities of RTLS Systems in Tourism Industry. Proceedings of SPIE, Photonics Applications in Astronomy, Communications, Industry, and High-Energy Physics Experiments, Wilga 2018, 108080C [DOI: $10.1117 / 12.2500558$

[13] Płaza M., Deniziak S., Płaza M., Belka R., Pięta P.: Analysis of Paralle Computational Models for Clustering. Proceedings of SPIE, Photonics Applications in Astronomy, Communications, Industry, and High-Energy Physics Experiments, Wilga 2018, 108081 O [DOI: 10.1117/12.2500795].

[14] Płaza M. Szcześniak Z. Dudek J.: Generation of medium frequency electrotherapeutic signals. Proceedings of SPIE, Photonics Applications in Astronomy, Communications, Industry, and High-Energy Physics Experiments, Wilga 2017, 104452T [DOI: 10.1117/12.2274764].

[15] Płaza M., Szcześniak Z.: Signal processing system for electrotherapy applications. Proceedings of SPIE, Photonics Applications in Astronomy, Communications, Industry, and High-Energy Physics Experiments, Wilga 2017, 104452W [DOI: 10.1117/12.2280095].

[16] Płaza M.: Chosen models of VCVS having parameters set digitally. Proceeding of SPIE, Photonics Applications in Astronomy, Communications, Industry, and High-Energy Physics Experiments, Wilga 2008, 71240N [DOI: 10.1117/12. 817952].

[17] Radu (Genete) L. D.: Internet of Things - A New Challenge for Environmenta Protection. The 26th IBIMA Conference on Innovation Management an Sustainable Economic Competitive Advantage: From Regional Development to Global Growth, Madrid 1/2015.

[18] Recommendation ITU-T Y.2060.: Series Y: Global Information Infrastructure, Internet Protocol Aspects and Next-Generation Networks, Next Generation Networks - Frameworks and Functional Architecture Models. ITU-T, Geneva 2013.

[19] Sai Jyothi B., Jyothi S.: A Study on Big Data Modeling Techniques. International Journal of Computer Networking, Wireless and Mobile Communications, TJPRC Pvt. Ltd. 5/2015, 19-26.

[20] Scully P.: The Top 10 IoT Segments in 2018 - based on 1,600 real IoT projects. IOT Analytics, February 22, 2018. https://iot-analytics.com/top-10-iotsegments-2018-real-iot-projects/ (available: 25.05.2019).

[21] Shakib Y, Kirby S.: 2015 Predictions: The highest-impact IoE advancements in Retail. Digital Transformation, January 16, 2015. https://blogs.cisco.com/digital/ 2015- predictions-the-highest-impact-ioe-advancements-in-retail (available: 27.05.2019)

[22] United Nations.: Transforming Our World: The 2030 Agenda for Sustainable Development A/RES/70/1. New York 2015.

[23] Ustundag A., Cevikcan E.: Industry 4.0: Managing The Digital Transformation Springer International Publishing, Switzerland 2018
[24] Wu X. et al.: A 0.04MM316NW Wireless and Batteryless Sensor System with Integrated Cortex-M0+ Processor and Optical Communication for Cellular Temperature Measurement. IEEE Symposium on VLSI Circuits, Honolul 2018, 191-192.

\section{Ph.D. Mirosław Plaza}

e-mail: m.plaza@tu.kielce.p

Researcher at the Kielce University of Technology. Head of the ICT and IoT Laboratory. He is strongly involved in the development of modern ICT at the Faculty of Electrical Engineering, Automatic Control and Computer Science. Author of 2 award-winning patents and over 50 scientific publications. He holds instructor's qualifications i.a.: CCNA, CCNASecurity, IoT (Connecting Things, Big Data).

ORCID ID: 0000-0001-9728-3630

\section{Ph.D. Radoslaw Belka}

e-mail: r.belka@tu.kielce.pl

The assistant professor at the Kielce University of Technology and certified instructor of the Cisco Networking Academy program. Head of the R\&D Grant no: POIR.04.01.02-00-0041/17 "Cybermatryca - an integrated tourist service system" dedicated to the use of IoE technology in the tourism industry. His work focuses on data analysis, electronic sensors and materials sciences.

ORCID ID: 0000-0002-6283-3724

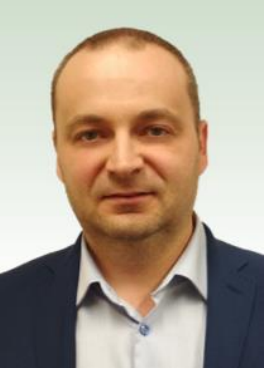

\section{Prof. Zbigniew Szcześniak}

e-mail: z.szczesniak@tu.kielce.pl

Employee of the Kielce University of Technology. His scientific and professional interests focus mainly on automation and electronics devices, as well as measurement systems used in the automation of technological processes. He is the author of over 110 scientific and rsesearch papers, including 3 monographs and 13 patents, as well as the promoter and reviewer of over a hundred diploma papers.

ORCID ID: 0000-0002-7896-3291

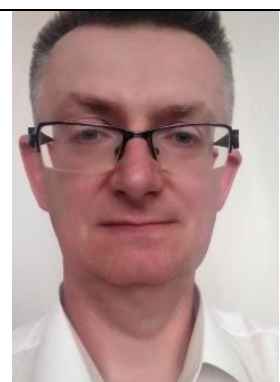

otrzymano/received: 15.05 .2019

przyjęto do druku/accepted: 15.06 .2019 